\title{
NARCOLEPSY IN A CHILD UNDER 7 YEARS OLD
}

\author{
BY \\ D. J. SALFIELD \\ From the Brambling House Children's Centre, Chesterfield
}

(RECEIVED FOR PUBLICATION MAY 19, 1959)

Narcolepsy is very rare. It begins almost always after the age of 10 years. Only two cases have been reported, as far as could be ascertained, at the age of 8 years, and this early onset was described as 'remarkable' (Kanner, 1957). It therefore appears justified to report this case.

\section{Case Report}

The patient was referred to the school medical officer at the age of 6 years as 'somewhat microcephalic' (head circumference $19 \mathrm{in}$.) 'and in need of special educational treatment'. Some months before he had been seen by an orthopaedic surgeon because of bad posture; he also had 'weak ankles and knees'. No organic disease was found. The advice that he should do postural exercises was not followed by the parents. Later the child was sent to an educational psychologist for further assessment, but he was variously assessed as having an I.Q. between 75 and 87 , i.e. in the 'dull and backward' range. The I.Q. did not quite account for his poor school attainments and, in view of further reports received, my attention was drawn to him.

His mother was thin and harassed-looking, of only moderate intelligence, less than sufficiently understanding of the child's needs, and she appeared inadequate. The health visitor had reported a lack of co-operation over measures suggested to raise the child's standard of wellbeing. 'She is willing, but does not seem able to get there'; 'has to have all arrangements made for her'. The family is well known to the local health authority. All six children in the family have poor health records. Three of them are of the mother's first marriage. The head teacher thinks they are all equally neglected.

The psychologist's report described the father as 'oafish-looking, contributing little to the conversation. Mother did not talk freely in his presence'. Another report stated: 'There is mismanagement of money. They have sufficient income but seem to be in debt.' Another said that the father is an irresponsible man; he left the mother twice, and she expects him to do so again. They used to live in rooms. Whenever the child cried his mouth had to be pressed with a towel lest the noise should be heard. They were frequently evicted. The Assistance Board used to help when the father went off on his spring-time wanderings, and the family were left without food. The universal verdict of the reports on the boy seemed to be that 'He is shy and timid'.
The head teacher described him as well-behaved because apathetic, sometimes stubborn, occasionally found to bully younger children, having a pinched and cowed look, and being ill-nourished and insufficiently clothed. He fell asleep at school each afternoon, which was thought possibly to be related to his not being sent to bed before the parents.

The family doctor reported, apart from childish ailments, frequent colds and upper respiratory infections. He felt that the home conditions from the matrimonial and psychological points of view were very poor. 'All the children appear pinched and cowed.'

My own examination did not contribute anything new. The child looked pale and in a poor state of nutrition; he was shy, fearful, and unintelligent. His gait was clumsy. He had a marked cervical and upper thoracic kyphosis, and the musculature was of poor tone.

The slowly elicited history contained no mention of illness which could be said to resemble encephalitis. There had been no head injuries. The mother said that during the last two years the boy had been suddenly dropping off to sleep several times a day. He frequently walked about 'half-dazed' at night. No history of cataplexy, etc. was obtained. While I was talking to him and his mother on one occasion the boy sank forward in his chair, his eyes closed, his impassive face becoming completely blank. After about two to three minutes he opened his eyes, was perfectly conscious and orientated, and did not seem to suffer any after-effects. There was no visible change of colour, tonus, etc. He seemed to have been normally asleep. Narcolepsy was then diagnosed.

A neurosurgeon, whose opinion was sought to exclude organic causes for the condition, reported a negative neurological examination. The electroencephalogram was reported to 'show a very slow tracing, mainly of $4 \mathrm{c} / \mathrm{s}$ with practically no alpha rhythm, without epileptic bursts'. The impression from the electroencephalogram was of a very immature cortex. Radiographs of the skull showed no abnormality.

Long-acting dexamphetamine (Dexten), $2.5 \mathrm{mg}$. in the morning, was prescribed but, as might have been expected from the family history, the patient failed to attend again.

\section{Discussion}

The criteria for the diagnosis of narcolepsy are ill-established and the classification of the various 
forms the disease may take is confused. The aetiology is equally uncertain.

Narcolepsy is the irresistible onset of sleep, which is indistinguishable from normal sleep. The sleep lasts sometimes for seconds, sometimes for a few minutes, rarely for hours. Most narcoleptics are said also to have cataplexy, the attacks following a strong emotional stimulus, when all voluntary muscles become flaccid. The patient sinks down but does not undergo an alteration of consciousness. So far the authors seem to be agreed.

Sleep paralysis, hypnagogic hallucinations and vivid dreams are said to be often associated with the two conditions. Yoss and Daly (1957) found, however, that of 241 cases observed during five years only $11 \%$ had the 'complete narcoleptic tetrad'; $68 \%$ had cataplexy, $24 \%$ sleep paralysis and $30 \%$ hypnagogic hallucinations. All authors seem agreed that the male sex predominates. Early waking, waking attacks, headaches and disturbances of the autonomic nervous system have been observed by Heyck (1955).

Often a distinction is made between symptomatic and idiopathic narcolepsy; and the psychogenicity of some cases has been postulated (Langworthy and Betz, 1944), as also cure by psychotherapy. Williamson (1951) thinks that in children it is nearly always a sequel of encephalitis. Hypoglycaemia has been implicated by Delay (1942). Association between epilepsy and narcolepsy is extremely rare. Kanner (1957) states that in the symptomatic attacks which occur chiefly in epidemic encephalitis and further in brain tumours, epilepsy and hysteria, the cataplectic component is absent'; while Coleman (1950) says ' $\ldots$ in cases of psychogenic origin narcolepsy is seldom accompanied by cataplexy', which is, presumably, his quotation from Lehrman and Weiss (1943).

As to the localization of possible lesions, Heyck (1955) states that tonus and sleep functions depend on the interlaminar areas of the thalamus, the hypothalamus and the mesencephalon. It seems likely that the central reticular formation of the brain stem, which has been shown to exert a desynchronizing (waking) effect on the cortex, could be involved.

The reported E.E.G. findings are contradictory. Most workers seem to have found no abnormality apart from the appearance of a deep sleep pattern. But epileptic-like patterns have been reported by some. Strauss, Ostow and Greenstein (1952) con- clude that these 'may be easily taken for bursts of slow activity'.

\section{Conclusion}

Our patient is remarkable in regard to the early age, probably 5 years, at which the disturbance began. No organic disease was detected in his present condition or history which would account for it, unless one of his many infectious diseases was accompanied by a subclinical encephalitis.

His electroencephalogram seems consistent with normality, if moderate immaturity. He has typical frequent sleep attacks of short duration. The sleep attack in which he was observed appeared indistinguishable from normal. Although no cataplexy, sleep paralysis or hypnagogic hallucinations have been demonstrated, these do not appear essential for the diagnosis of narcolepsy. The 'half-dazed' state in which he walks about at night may well be the consequence of frightening but not recollected dreams. The psychological state of the family group is consistent with the development in the child of a psychogenic type of narcolepsy. His low intelligence and the poor co-operation of the parents makes a psychotherapeutic approach unpromising. It was not possible to assess the effect of dexamphetamine, which, as well as similar drugs, has been recommended as the only measure, apart from psychotherapy, which alleviates the condition.

Thanks are due to the various writers of reports and particularly to Mr. James Hardman, neurological surgeon to the United Sheffield Hospitals.

\section{REFERENCES}

Coleman, S. M. (1950). In Recent Progress in Psychiatry, ed. G. W. T. H. Fleming, Vol. 2, p. 254. Churchill, London.

Delay, J. (1942). Ann. mét.-psychol., 100 (2), 375.

Heyck, H (1955). Dtsch med.Wschr. 80,1524.

Kanner, L. (1957). Child Psychiatry, 3rd ed. Thomas, Springfield, Illinois.

Langworthy, O. R. and Betz, B. J. (1944). Psychosom. Med., 6, 211. Lehrman, S. R. and Weiss, E. J. (1943). Psychiat. Quart., 17, 135.

Strauss, H., Ostow, M. and Greenstein, L. (1952). Diagnostic. Electroencephalography. Grune and Stratton, New York.

Williamson, B. (1951). A Handbook on Diseases of Children, 6th ed. Livingstone, Edinburgh.

Yoss, R. E. and Daly, D. D. (1957). Proc. Mayo Clin., 32, 320. Quoted from The Year Book of Neurology, Psychiatry and Neurosurgery, 1957-58, p. 199. The Year Book Publication, Chicago.

\section{Addendum}

Since this article was written, the boy has been admitted to a hostel for maladjusted children where he received $2.5 \mathrm{mg}$. Dexten in the morning for four months. During that time he was observed in two attacks. These have not recurred for two months now since discontinuing the drug, but he is in better physical and mental condition than before. 